\title{
Associations between Brain-Derived Neurotrophic Factor Plasma Levels and Severity of the IIIness, Recurrence and Symptoms in Depressed Patients
}

\author{
Liliana Dell'Osso Alessandro Del Debbio Antonello Veltri Carolina Bianchi \\ Isabella Roncaglia Marina Carlini Gabriele Massimetti Mario Catena Dell'Osso \\ Chiara Vizzaccaro Donatella Marazziti Armando Piccinni
}

Dipartimento di Psichiatria, Neurobiologia, Farmacologia e Biotecnologie, University of Pisa, Pisa, Italy

\section{Key Words}

Brain-derived neurotrophic factor, plasma levels •

Major depression, recurrence $\cdot$ Hamilton Rating

Scale for Depression retardation factor score .

Depersonalization/derealization symptoms

\begin{abstract}
Background: There is increasing evidence that the brain-derived neurotrophic factor (BDNF) is involved in the pathophysiology of mood disorders and that its peripheral levels represent a reliable mirror of its concentration in the brain. The aim of the present study was to measure BDNF plasma levels in patients affected by major depression and to explore the possible relationship between the biological parameter and characteristics of the illness. Method: BDNF plasma levels were evaluated in 30 inpatients suffering from major depression, according to DSM-IV criteria, by means of a commonly employed ELISA method. The clinical characteristics were assessed by the Hamilton Rating Scale for Depression (HRSD) and the Clinical Global Impression Scale. Results: BDNF plasma levels were significantly lower in the patients with the severest illness compared with the others, and the same was true for patients with dissociative symptoms, severe sleep disturbance and recurrent depression. A significant and negative correlation was observed between the biological parameter and the retardation factor score of
\end{abstract}

the HRSD. Conclusion: These findings suggest that low BDNF levels are related to both recurrence and severity of depression, as well as to symptoms typical of dysfunctions of the hypothalamic-pituitary-adrenal axis.

Copyright $\odot 2010$ S. Karger AG, Basel

\section{Introduction}

Over the past decades, different findings suggested that the brain-derived neurotrophic factor (BDNF) might be involved in the pathophysiology of mood disorders [14]. $\mathrm{BDNF}$ is a neurotrophin recognized to mediate the survival, differentiation and outgrowth of selected neurons during development and adulthood, as well as to modulate the synaptic functions and the neuronal plasticity in several brain areas. BDNF is also present in peripheral tissues, is mainly stored in human platelets and circulates in plasma at levels 100 -fold lower than those of serum [5]; therefore, it has been suggested that the difference between serum and plasma BDNF may correspond to the amount of BDNF stored in circulating platelets [6]. Although the regulation of this neurotrophin in plasma is still poorly understood and there exist other potential sources contributing to its plasma levels including vascular endothelial and smooth muscle cells, activated macrophages and lymphocytes, the amount of plasma BDNF

\section{KARGER}

Fax +4161306 1234 E-Mail karger@karger.ch www.karger.com

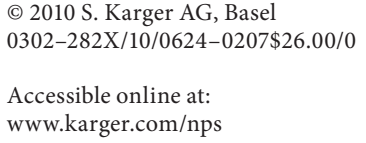

Donatella Marazziti, MD

Dipartimento di Psichiatria, Neurobiologia, Farmacologia e Biotecnologie

University of Pisa, Via Roma 67

IT-56100 Pisa (Italy)

Tel. +39 050221 9768, Fax +39050 221 9787, E-Mail dmarazzi@psico.med.unipi.it 
Table 1. Characteristics of the patients

\begin{tabular}{lc}
\hline Age (mean \pm SD), years & $45.9 \pm 14.8$ \\
Age at onset (mean \pm SD), years & $31 \pm 14$ \\
Female & $19(63.3 \%)$ \\
Male & $11(36.7 \%)$ \\
Psychotic & $8(26.7 \%)$ \\
Nonpsychotic & $22(73.3 \%)$ \\
HRSD score (mean \pm SD) & $24.43 \pm 5.78$ \\
CGI score (mean \pm SD) & $4.79 \pm 0.83$ \\
HRSD factor score (mean \pm SD) & \\
$\quad$ Anxiety/somatization & $1.3 \pm 0.35$ \\
$\quad$ Weight & $0.5 \pm 0.73$ \\
$\quad$ Cognitive disturbance & $0.82 \pm 0.50$ \\
$\quad$ Diurnal variation & $0.58 \pm 0.63$ \\
$\quad$ Retardation & $1.89 \pm 0.78$ \\
Sleep disturbance & $0.74 \pm 0.47$ \\
Plasma BDNF levels (mean $\pm \mathrm{SD}), \mathrm{pg} / \mathrm{ml}$ & $2,539.62 \pm 1,616.98$ \\
\hline
\end{tabular}

has been considered to partly reflect its secretion in the central nervous system [7]. In fact, conflicting results have been obtained concerning the relationship between central and peripheral BDNF concentrations in rodents $[8,9]$. Studies of BDNF uptake or transport across the blood-brain barrier have been mixed and additional data are needed to support the existence of an active transport system for uptake of BDNF into the brain [10].

Recently, in depressed patients lower BDNF plasma and/or serum concentrations have been detected than in healthy control subjects [11-17], which return to normal levels after successful treatments [18-21]. However, such BDNF changes do not appear to be depression-specific, as they have been described in other psychiatric illnesses [22-24] and generally interpreted as a state-dependent marker or an index of stress [10]. Alternatively, BDNF changes in depression have been linked to clinical characteristics, such as severity of the illness [11], or presence of psychotic symptoms [15]. However, the ensuing findings emerging from the different studies are not easily comparable, because the BDNF was evaluated in plasma or serum, and the patient samples were heterogenous (treated and not treated, or with different washout periods) $[25,26]$. Moreover, generally, the intake of psychotropic drugs by patients with mood disorders has been considered a source of potential bias [27], as some evidence suggests that antidepressants normalize serum BDNF levels $[20,28]$, although opposite data are also available [19]. Recently, decreased BDNF levels have been reported in euthymic patients with unipolar and bipolar depression, irrespective of the medications [29].
However, one of the main limitations of the studies exploring the relationship between BDNF and neuropsychiatric disorders is linked to the extent to which blood BDNF levels may reflect brain BDNF concentrations. In fact, serum BDNF may be affected by the amount of BDNF stored in platelets and plasma BDNF has shown high interindividual variability [7]. In any case, it has been suggested that peripheral BDNF may influence brain function and behavior [10].

In view of the paucity of information and controversies about the relationship between BDNF levels and characteristics of depression, the aim of the present study was to explore BDNF plasma levels in depressed patients well-characterized from the clinical point of view, and to explore the possible relationships between the biological parameter and illness features and symptoms.

\section{Methods}

Subjects

Thirty in- and outpatients of both sexes (19 women and 11 men, aged between 22 and 65 years, mean \pm SD: $45.9 \pm 14.8$ ) were recruited at the Dipartimento di Psichiatria, Neurobiologia, Farmacologia e Biotecnologie, University of Pisa, Italy, between September 2006 and December 2008, and consecutively enrolled in the study (table 1). All patients were suffering from a current major depressive episode, single $(n=6)$ or recurrent $(n=24)$, diagnosed according to the Diagnostic and Statistical Manual for Mental Disorders criteria [30]. The diagnosis was confirmed by means of the Mini International Neuropsychiatric Interview [31]. Exclusion criteria included the presence of organic brain disorder, substance abuse, pregnancy or any severe or chronic physical illness. Patients had been either medication-naïve $(n=6)$ or medication-free for approximately 1 year $(n=19)$, or at least for 2 weeks $(\mathrm{n}=5)$.

No woman took contraceptive drugs; 6 women were in menopause. Blood from all the fertile women was drawn in the midfollicular phase.

The severity of depression was assessed by means of the 21item Hamilton Rating Scale for Depression (HRSD) [32] and the Clinical Global Impression (CGI) severity of illness scale [33]. Patients had an HRSD total score of $24.4 \pm 5.7$ and a CGI score of $4.8 \pm 0.8$.

All patients provided informed written consent to the study which was approved by the Ethics Committee of the University of Pisa in accordance with the Declaration of Helsinki (1996) and with the guidelines of the Good Clinical Practice (1995).

\section{BDNF Assay}

Ten milliliters of venous blood were drawn in the morning, between 8:00 and 9:00 a.m., following an overnight fast, into EDTA-coated tubes that were kept on ice, centrifuged at $2,000 \mathrm{~g}$ for $10 \mathrm{~min}$ at $4{ }^{\circ} \mathrm{C}$ and refrigerated at $-20^{\circ} \mathrm{C}$. To measure the amount of total BDNF, acidification and subsequent neutralization of the samples were followed before proceeding with the ELI- 


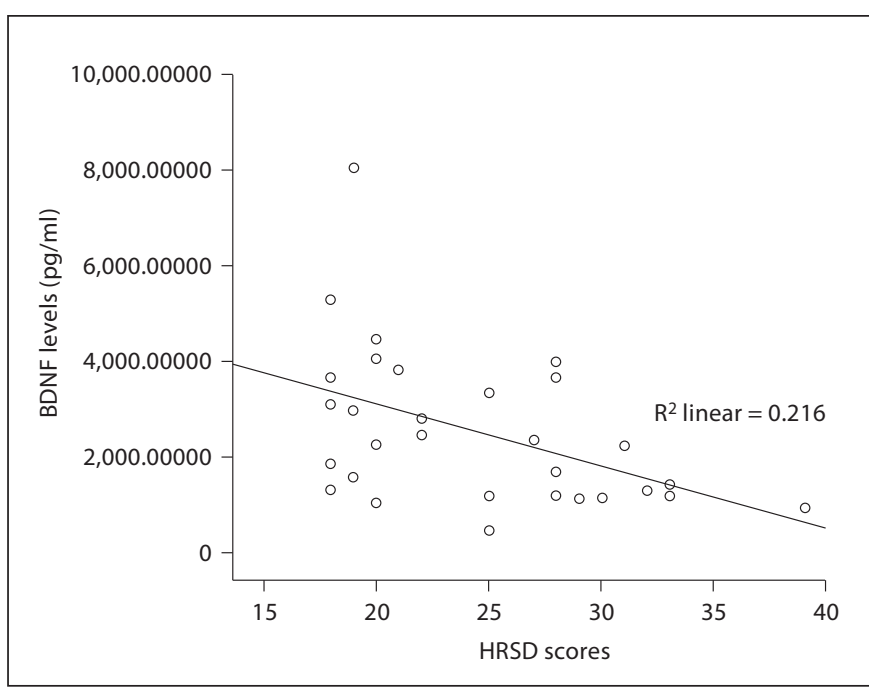

Fig. 1. Relationship between HRSD total scores and BDNF plasma levels.

SA protocol, according to the manufacturer's instruction (Promega, Wallisellen, Switzerland). 96-well plates were coated with anti-BDNF monoclonal antibody and incubated at $4{ }^{\circ} \mathrm{C}$ for $18 \mathrm{~h}$. The plates were incubated in a blocking buffer for $1 \mathrm{~h}$ at room temperature, then samples were added. The samples and BDNF standards were maintained at room temperature under shaking for $2 \mathrm{~h}$, followed by washing with the appropriate buffer. The plates were successively incubated with anti-human BDNF polyclonal antibody at room temperature for $2 \mathrm{~h}$, washed and incubated with anti-IgG antibody conjugated to horseradish peroxidase for $1 \mathrm{~h}$ at room temperature. The plates were incubated in peroxidase substrate and tetramethylbenzidine solution to produce a color reaction. The reaction was stopped with $1 \mathrm{M} \mathrm{HCl}$. The absorbance at $450 \mathrm{~nm}$ was measured with a microplate reader (Model 550, Bio Rad Laboratories) to determine BDNF values that are expressed as picograms per milliliter.

Statistical Analyses

Since BDNF levels and HRSD scores were not normally distributed, nonparametric tests were used. To compare these variables amongst multiple or 2 independent samples, the KruskalWallis and the Mann-Whitney tests were used, respectively. To analyze the relationships between variables, the Spearman's coefficient was computed. A p value of $<0.05$ was judged as statistically significant. All analyses were carried out using the SPSS version 14.0 , by means of personal computer programs.

\section{Results}

Table 1 shows the sociodemographic and clinical variables and the plasma BDNF values of the sample.

No significant difference was detected in age, plasma BDNF levels, and HRSD total and factor scores between

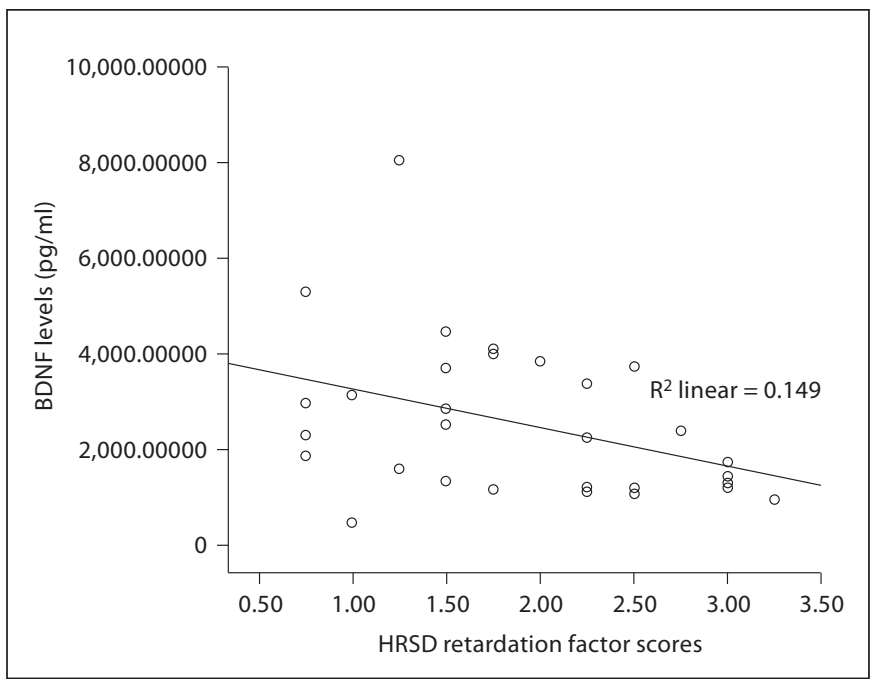

Fig. 2. Relationship between HRSD retardation factor scores and BDNF plasma levels.

men and women. Significant and negative correlations were observed between BDNF levels (mean $\pm \mathrm{SD}, \mathrm{pg} / \mathrm{ml}$ ) and the HRSD total or retardation factor scores $(\mathrm{r}=$ $-0.483, p=0.007$ and $r=-0.397, p=0.030$, respectively) (fig. 1,2). Moreover, after categorizing the sample on the basis of the 75th percentile of the HRSD sleep disturbance factor score (equal to 1), significantly lower BDNF levels were observed in those patients $(n=6)$ with the highest HRSD sleep disturbance factor scores $(1,231.62 \pm 629.79$ vs. $2,866.62 \pm 1,628.66 ; \mathrm{Z}=-2.826, \mathrm{p}=0.005$ ) (table 2 ). When the patients were divided into those with and those without dissociative symptoms, the patients $(n=13)$ of the first group showed significantly lower plasma BDNF levels than those of the second $(1,910.97 \pm 1,054.47 \mathrm{vs}$. $3,020.35 \pm 1,827.13 ; Z=-2.009, p=0.045)$.

As far as the CGI is concerned, BDNF levels differed significantly amongst the various groups ['moderately ill' (score $=4$ on the CGI severity of illness scale; $\mathrm{n}=13$ ): $2,780.54 \pm 1,353.42$; 'markedly ill' (score $=5 ; \mathrm{n}=10$ ): $2,573.86 \pm 2,155.80$; 'severely ill' (score $=6 ; \mathrm{n}=7$ ): $1,213.23 \pm 158.68 ; \chi^{2}=4.350 ; p=0.023$ ]. Between-group comparisons showed that the severely ill patients scored significantly lower than the moderately ill $(Z=-2.656$, $\mathrm{p}=0.008$ ). Furthermore, the 24 patients with recurrent episodes of depression showed significantly lower BDNF levels than those with a single episode $(2,112.49 \pm$ $1,168.59$ vs. $4,248.14 \pm 2,122.38 ; \mathrm{Z}=-2.489, \mathrm{p}=0.013)$. Finally, no correlation was observed between plasma BDNF levels and diagnosis, presence of psychosis or age of onset (table 2). 
Table 2. Plasma BDNF levels and clinical features in depressed patients

\begin{tabular}{|c|c|c|c|c|}
\hline & $\mathrm{n}$ & $\begin{array}{l}\text { BDNF levels } \\
\text { (mean } \pm \text { SD), pg/ml }\end{array}$ & $\mathrm{Z}$ & $\mathrm{p}$ \\
\hline Moderately ill patients (CGI score $=4$ ) & 13 & $2,780.54 \pm 1,353.42$ & -2.656 & 0.008 \\
\hline Severely ill patients (CGI score $=6$ ) & 7 & $1,213.23 \pm 158.68$ & & \\
\hline Low sleep disturbance factor score & 24 & $2,866.62 \pm 1,628.66$ & -2.826 & 0.005 \\
\hline High sleep disturbance factor score & 6 & $1,231.62 \pm 629.79$ & & \\
\hline Absence depersonalization/derealization item & 17 & $3,020.35 \pm 1,827.13$ & -2.009 & 0.045 \\
\hline Presence depersonalization/derealization item & 13 & $1,910.97 \pm 1,054.47$ & & \\
\hline Single episode & 6 & $4,248.14 \pm 2,122.38$ & -2.489 & 0.013 \\
\hline Recurrence & 24 & $2,112.49 \pm 1,168.59$ & & \\
\hline
\end{tabular}

Given that our sample was composed of some patients with a shorter period of drug washout (at least for 2 weeks, $n=5$ ), we further replicated our analyses while eliminating these subjects from the total sample. In this case, too, HRSD total and retardation factor scores showed the same significant negative correlations with BDNF levels $(\mathrm{r}=-0.509, \mathrm{p}=0.007$ and $\mathrm{r}=-0.384, \mathrm{p}=0.048$, respectively). Moreover, the highest HRSD sleep disturbance factor scores were associated with lower BDNF levels $(1,187.62 \pm 306.57$ vs. $3,402.75 \pm 1,697.90, Z=-3.723$, $\mathrm{p}=0.000)$. In addition, patients with dissociative symptoms $(\mathrm{n}=12)$ showed significantly lower plasma BDNF levels than those without them $(1,737.67 \pm 887.19$ vs. $3,065.63 \pm 2,020.19 ; Z=-1.986, p=0.047)$. Finally, BDNF levels differed significantly amongst the CGI scoring groups ['moderately ill' $(\mathrm{n}=8): 3,030.90 \pm 1,309.31$; 'markedly ill' $(\mathrm{n}=10): 2,573.86 \pm 2,155.80$; 'severely ill' $\left.(\mathrm{n}=7): 1,213.23 \pm 158.68 ; \chi^{2}=7.096 ; \mathrm{p}=0.029\right]$; differences in BDNF levels between patients with recurrent episodes of depression $(n=20)$ and those with a single episode were close to significance $(Z=-1.835 ; \mathrm{p}=0.067)$.

\section{Discussion}

The present study led to different findings. First, we observed significant negative correlations between the severity of illness, as rated by the HRSD total score, and plasma BDNF levels, that is to say, the severer the patient's illness, the lower the biological parameter. This finding is consistent with previous data gathered in drug-free depressed patients [11, 14], but at variance with others [15]. The link between BDNF and depression is hence supported by our observation that the plasma levels of the 'severely ill' patients were significantly lower than those of the 'moderately ill' ones.
Although there is evidence suggesting an important role of BDNF in the pathophysiology of mood disorders and response to antidepressant medications [11-18, 20, 21], conflicting results have been gathered on this topic. For example, a recent study reported no significant difference in peripheral BDNF concentrations comparing BDNF levels in depressed patients before and after antidepressant treatment [19]. Moreover, there is little information about the source of BDNF in the blood, and studies about the relationship between brain and blood BDNF levels have led to conflicting findings $[8,9]$.

Second, even the HRSD retardation factor scores correlated negatively with BDNF levels. According to us, this is an intriguing finding, because psychomotor retardation is considered a core symptom of depression and has generally been linked to the severity of illness [34], or to melancholia [35]. From a neurobiological point of view, it has been shown that some phenotypes of depressive patients, including the melancholic phenotype, are characterized by a more marked disturbance of the hypothalamic-pituitary-adrenal (HPA) axis, as compared with the others $[36,37]$. The influence of corticosteroid hormones on BDNF expression has been shown in preclinical studies which reported how cortisol may exert a downregulation on BDNF synthesis in the central nervous system [38].

Third, lower BDNF plasma levels were found in those patients with the severest sleep disturbance. Links between sleep disturbance and depression are known all along: about three quarters of depressed patients complain of sleeplessness that provokes subjective distress, impairment of quality of life, and represents a strong risk factor for suicide and recurrence [39]. Moreover, an HPA overdrive, as observed especially in depressed patients with melancholic features, appears to be related to dysregulations of sleep [40]. Interestingly, a recent study in 
rats suggests a relationship between the synaptic plasticity and the homeostasis of sleep, while identifying BDNF as a major mediator of this link at the molecular level [41].

Fourth, we found lower BDNF concentrations in patients with depersonalization/derealization symptoms: this is consistent with a similar observation gathered in patients affected by burnout, a syndrome characterized by chronic stress [42]. This finding may represent another indicator of the relationships between BDNF and stress systems, as dysregulations of the HPA axis have been reported in patients with depersonalization [43].

Fifth, in agreement with a previous study [15], patients who were suffering from a recurrent episode had significantly lower levels of BDNF. It should, however, be underlined that the patients with a single episode of our sample were not as numerous as those with recurrent episodes, so that the results of the statistical analysis may not be considered totally reliable.

This study suffers several limitations that should be acknowledged. The most important is that the sample size was small, included mainly women and some underwent a short washout period. Another problem is related to the extent to which blood BDNF levels may reflect brain BDNF concentrations. We chose to investigate BDNF in plasma, because platelet-poor plasma BDNF seems to be minimally affected by the amount of BDNF stored in platelets and, therefore, may represent a more reliable and sensitive marker of BDNF variations occurring in the brain and periphery [7]. Nevertheless, plasma BDNF has shown high interindividual variability. It should also be mentioned that our absolute plasma BDNF values were higher than those observed in recent publications [7, 44]. However, as previously reported [45], we assayed total BDNF in plasma by the acidification and neutralization procedures, while others might have measured the amount of the free mature form. Therefore, according to us, different methodological procedures might contribute to explain the controversial data present in the literature $[25,26]$. The mature form and the precursor form of BDNF play different roles in cell survival, synaptic plasticity and cognitive functions in health and pathology [46]. In animals, we recently showed that the mature, but not the precursor form of BDNF was significantly increased in the prefrontal cortex of rats treated for 14 days with duloxetine at $30 \mathrm{mg} / \mathrm{kg} /$ day [47].

The use of medications has always been considered a confounding factor in the measurements of BDNF levels in mood disorders [27]. In our study, however, we found no difference in a further replication of the analyses by excluding patients with a 2 -week washout. Interestingly, decreased BDNF levels have been reported in both treated and untreated euthymic patients with unipolar and bipolar depression (types I and II) [29].

In conclusion, our results showed that lower BDNF levels may be associated with both recurrence and severity of depression, as well as with symptoms suggesting dysregulations of the HPA axis. Further studies are needed to elucidate more thoroughly the involvement of BDNF in the pathophysiology of symptom patterns or dimensions that may well be present in a broad range of neuropsychiatric conditions.

\section{References}

1 Duman RS, Heninger GR, Nestler EJ: A molecular and cellular theory of depression. Arch Gen Psychiatry 1997;54:597-605.

2 Duman RS: Role of neurotrophic factors in the etiology and treatment of mood disorders. Neuromol Med 2004;5:11-25.

-3 Post RM: Role of BDNF in bipolar and unipolar disorder: clinical and theoretical implications. J Psychiatr Res 2007;41:979-990.

-4 Stein DJ, Daniels WM, Savitz J, Harvey BH: Brain-derived neurotrophic factor: the neurotrophin hypothesis of psychopathology. CNS Spectr 2008;13:945-949.

5 Yamamoto H, Gurney ME: Human platelets contain brain-derived neurotrophic factor. J Neurosci 1990;10:3469-3478.
-6 Fujimura H, Altar CA, Chen R, Nakamura T, Nakahashi T, Kambayashi J, Sun B, Tandon $\mathrm{NN}$ : Brain-derived neurotrophic factor is stored in human platelets and released by agonist stimulation. Thromb Haemost 2002; 87:728-734.

7 Lommatzsch M, Zingler D, Schuhbaeck K, Schloetcke K, Zingler C, Schuff-Werner P: The impact of age, weight and gender on BDNF levels in human platelets and plasma. Neurobiol Aging 2005;26:115-123.

8 Karege F, Schwald M, Cisse M: Postnatal developmental profile of brain-derived neurotrophic factor in rat brain and platelets. Neurosci Lett 2002;328:261-264.
9 Elfving B, Plougmann $\mathrm{PH}$, Müller HK, Mathé AA, Rosenberg R, Wegener G: Inverse correlation of brain and blood BDNF levels in a genetic rat model of depression. Int $\mathrm{J}$ Neuropsychopharmacol, E-pub ahead of print.

10 Sen S, Duman R, Sanacora G: Serum brainderived neurotrophic factor, depression, and antidepressant medications: meta-analyses and implications. Biol Psychiatry 2008;64: 527-532.

11 Shimizu E, Hashimoto K, Okamura N, Koike K, Komatsu N, Kumakiri C, Nakazato M, Watanabe H, Shinoda N, Okada S, Iyo M: Alterations of serum levels of brain-derived neurotrophic factor (BDNF) in depressed patients with or without antidepressants. Biol Psychiatry 2003;54:70-75. 
12 Aydemir O, Deveci A, Taneli F: The effect of chronic antidepressant treatment on serum brain-derived neurotrophic factor levels in depressed patients: a preliminary study. Prog Neuropsychopharmacol Biol Psychiatry 2005;29:261-265.

13 Gervasoni N, Aubry JM, Bondolfi G, Osiek C, Schwald M, Bertschy G, Karege F: Partial normalization of serum brain-derived neurotrophic factor in remitted patients after a major depressive episode. Neuropsychobiology 2005;51:234-238.

-14 Gonul A, Akdeniz F, Taneli F, Donat O, Eker C, Vahip S: Effect of treatment on serum brain-derived neurotrophic factor levels in depressed patients. Eur Arch Psychiatry Clin Neurosci 2005;255:381-386.

15 Lee BH, Kim H, Park SH, Kim YK: Decreased plasma BDNF level in depressive patients. J Affect Disord 2007;101:239-244.

-16 Piccinni A, Marazziti D, Catena M, Domenici L, Del Debbio A, Bianchi C, Mannari C, Martini C, Da Pozzo E, Schiavi E, Mariotti A, Roncaglia I, Palla A, Consoli G, Giovannini L, Massimetti G, Dell'Osso L: Plasma and serum brain-derived neurotrophic factor (BDNF) in depressed patients during 1 year of antidepressant treatments. J Affect Disord 2008;105:279-283.

- 17 Matrisciano F, Bonaccorso S, Ricciardi A, Scaccianoce S, Panaccione I, Wang L, Ruberto A, Tatarelli R, Nicoletti F, Girardi P, Shelton RC: Changes in BDNF serum levels in patients with major depression disorder (MDD) after 6 months treatment with sertraline, escitalopram, or venlafaxine. J Psychiatr Res 2009;43:247-254.

18 Marano CM, Phatak P, Vemulapalli UR, Sasan A, Nalbandyan MR, Ramanujam S, Soekadar S, Demosthenous M, Regenold WT: Increased plasma concentration of brain-derived neurotrophic factor with electroconvulsive therapy: a pilot study in patients with major depression. J Clin Psychiatry 2007;68:512-517.

-19 Yoshimura R, Mitoma M, Sugita A, Hori H, Okamoto T, Umene W, Ueda N, Nakamura $\mathrm{J}$ : Effects of paroxetine or milnacipran on serum brain-derived neurotrophic factor in depressed patients. Prog Neuropsychopharmacol Biol Psychiatry 2007;31:1034-1037.

20 Huang TL, Lee CT, Liu YL: Serum brain-derived neurotrophic factor levels in patients with major depression: effects of antidepressants. J Psychiatr Res 2008;42:521-525.

-21 Piccinni A, Del Debbio A, Medda P, Bianchi C, Roncaglia I, Veltri A, Zanello S, Massimetti E, Origlia N, Domenici L, Marazziti D, Dell'Osso L: Plasma brain-derived neurotrophic factor in treatment-resistant depressed patients receiving electroconvulsive therapy. Eur Neuropsychopharmacol 2009; 19:349-355

-22 Rizos EN, Rontos I, Laskos E, Arsenis G, Michalopoulou PG, Vasilopoulos D, Gournellis $\mathrm{R}$, Lykouras L: Investigation of serum BDNF levels in drug-naive patients with schizo- phrenia. Prog Neuropsychopharmacol Biol Psychiatry 2008;32:1308-1311.

23 Dell'Osso L, Carmassi C, Del Debbio A, Catena Dell'Osso M, Bianchi C, Da Pozzo, E, Origlia N, Domenici L, Massimetti G, Marazziti D, Piccinni A: Brain-derived neurotrophic factor plasma levels in patients suffering from post-traumatic stress disorder. Prog Neuropsychopharmacol Biol Psychiatry 2009;33:899-902.

24 Saito S, Watanabe K, Hashimoto E, Saito T: Low serum BDNF and food intake regulation: a possible explanation of the pathophysiology of eating disorders. Prog Neuropsychopharmacol Biol Psychiatry 2009;33: 312-316.

25 Karege F, Bondolfi G, Gervasoni N, Schwald M, Aubry JM, Bertschy G: Low brain-derived neurotrophic factor (BDNF) levels in serum of depressed patients probably results from lowered platelet BDNF release unrelated to platelet reactivity. Biol Psychiatry 2005;57: 1068-1072.

26 Palomino A, Vallejo-Illarramendi A González-Pinto A, Aldam A, González Gómez, C, Mosquera F, González-García G, Matute C: Decreased levels of plasma BDNF in first episode schizophrenia and bipolar disorder patients. Schizophr Res 2006;86: 321-322.

27 de Oliveira GS, Ceresér KM, Fernandes BS, Kauer-Sant'anna M, Fries GR, Stertz L, Aguiar B, Pfaffenseller B, Kapczinski F: Decreased brain-derived neurotrophic factor in medicated and drug-free bipolar patients. J Psychiatr Res 2009;43:1171-1174.

28 Gonul AS, Akdenz F, Taneli A, Donat O, Eker C, Vahip S: The effect of treatment on serum brain-derived neurotrophic factor in depressed patients. Eur Neuropsychopharmacol 2003;3:S20-S23.

29 Monteleone P, Serritella C, Martiadis V, Maj M: Decreased levels of serum brain-derived neurotrophic factor in both depressed and euthymic patients with unipolar depression and in euthymic patients with bipolar I and II disorders. Bipolar Disord 2008;10:95100.

30 American Psychiatric Association: Diagnostic and Statistical Manual of Mental Disorders, Text Revision, ed 4. Washington, American Psychiatric Press, 2000.

31 Sheehan DV, Lecrubier Y, Sheehan KH, Amorim P, Janavs J, Weiller E: The MiniInternational Neuropsychiatric Interview (M.I.N.I.): the development and validation of a structured diagnostic psychiatric interview for DSM-IV and ICD-10. J Clin Psychiatry 1998;59:22-33.

32 Hamilton M: A rating scale for depression. J Neurol Neurosurg Psychiatry 1960;23:5662.

33 Guy W: ECDEU Assessment Manual for Psychopharmacology. US Dept Health, Education, and Welfare Publication (ADM). Rockville, National Institute of Mental Health, 1976.
34 Benazzi F: Psychomotor changes in melancholic and atypical depression: 1976 unipolar and bipolar-II subtypes. Psychiatry Res 2002; 112:211-220.

35 Parker G: Classifying depression: should paradigms lost be regained? Am J Psychiatry 2000;157:1195-1203.

-36 Pintor L, Torres X, Navarro V, Martinez de Osaba MA, Matrai S, Gastó C: Corticotropin-releasing factor test in melancholic patients in depressed state versus recovery: a comparative study. Prog Neuropsychopharmacol Biol Psychiatry 2007;31:1027-1033.

\37 Pintor L, Torres X, Navarro V, Martinez de Osaba MA, Matrai S, Gastó C: Prediction of relapse in melancholic depressive patients in a 2-year follow-up study with corticotropin releasing factor test. Prog Neuropsychopharmacol Biol Psychiatry 2009;33:463-469.

-38 Schaff MJ, Duurland R, De Kloet ER, Vreugdenhil E: Circadian variation in BDNF mRNA expression in the rat hippocampus. Brain Res Mol Brain Res 2000;75:342-344.

39 Nutt D, Wilson S, Paterson L: Sleep disorders as core symptoms of depression. Dialogues Clin Neurosci 2008;10:329-336.

$\checkmark 40$ Antonijevic I: HPA axis and sleep: identifying subtypes of major depression. Stress 2008;11:15-27

41 Huber R, Tononi G, Cirelli C: Exploratory behavior, cortical BDNF expression, and sleep homeostasis. Sleep 2007;30:129-139.

42 Onen Sertoz O, Tolga Binbay I, Koylu E, Noyan A, Yildirim E, Elbi Mete $\mathrm{H}$ : The role of BDNF and HPA axis in the neurobiology of burnout syndrome. Prog Neuropsychopharmacol Biol Psychiatry 2008;32:1459-1466.

43 Simeon D, Guralnik O, Knutelska M, Hollander E, Schmeidler J: Hypothalamic-pituitary-adrenal axis dysregulation in depersonalization disorder. Neuropsychopharmacology 2001;25:793-795.

44 Begliuomini S, Lenzi E, Ninni F, Casarosa E, Merlini S, Pluchino N, Valentino V, Luisi S, Luisi M, Genazzani AR: Plasma brain-derived neurotrophic factor daily variations in men: correlation with cortisol circadian rhythm. J Endocrinol 2008;197:429-435.

45 Piccinni A, Marazziti D, Del Debbio A, Bianchi C, Roncaglia I, Mannari C, Origlia N, Catena Dell'Osso M, Massimetti G, Domenici L, Dell'Osso L: Diurnal variations of plasma brain-derived neurotrophic factor (BDNF) in humans. A gender analysis. Chronobiol Int 2008;25:819-826.

46 Martinowich K, Manji H, Lu B: New insights into BDNF function in depression and anxiety. Nat Neurosci 2007;10:1089-1093.

$\checkmark 47$ Mannari C, Origlia N, Scatena A, Del Debbio A, Catena M, Dell'Agnello G, Barraco A, Giovannini L, Dell'Osso L, Domenici L, Piccinni A: BDNF level in the rat prefrontal cortex increases following chronic but not acute treatment with duloxetine, a dual acting inhibitor of noradrenaline and serotonin reuptake. Cell Mol Neurobiol 2008;28:457468 . 